EM

SAQUET, Marcos Aurelio; SPOSITO, Eliseu Savério (Orgs.). Territórios e territorialidades: teorias, processos e conflitos. 2. ed. Rio de Janeiro: Consequência, 2015.

\title{
TERRITÓRIOS E TERRITORIALIDADES: TEORIAS, PROCESSOS E CONFLITOS
}

\section{TERRITORIES AND TERRITORIALITIES: THEORIES, PROCESSES AND CONFLICTS}

Arthur Breno STÜRMER ${ }^{1}$

Marcos Saquet e Eliseu Sposito são, reconhecidamente, dois nomes importantes do cenário acadêmico nacional, seja pela produção teórica individual e coletiva, seja pelos projetos de grande envergadura que os colocam na vanguarda de uma autêntica práxis geográfica. Parceiros de longa data, eles se reencontraram para reeditar uma obra que já completa uma década. A primeira deste tipo, Território e desenvolvimento: diferentes abordagens, também trazia a marca que vem caracterizando ambos os autores: a teoria e prática em torno do conceito de território, com o diferencial de conseguirem reunir novamente Rogério Haesbaert e Álvaro Heidrich na mesma obra para ampliar o debate sobre o território - desta vez, territórioS. Chamam, ainda, "clássicos" como Raffestin e Quaini, que logram servir de referências indispensáveis.

Em Territórios e territorialidades: teorias, processos e conflitos fica evidente a disposição em contribuir com a qualificação do debate que não se furta às colisões com o movimento do real, que é quando a teoria aplicada mostra seu valor interpretativo, propositivo e até interventivo. Por isso as teorias apresentadas se debruçam sobre processos de vários tipos, em recortes analíticos distintos e articulações escalares diversas. Nisso o conflito é antes elemento que compõe o território que algo à parte.

Se há um centro de gravidade na obra, ele recai sobre o território enquanto conceito. Não que permaneça sobre ele o tempo todo. Pelo contrário, os percursos mais ou menos . longos por temáticas correlatas faz do livro uma obra dinâmica e interessante para quem queira se aprofundar no assunto. Começa por destacar a experiência de Claude Raffestin em artigo basilar já no capítulo 1 e, na sequência, Luca Muscarà, comentando no capítulo 2, aspectos da obra de Jean Gottmann - autor que integra o rol de geógrafos italianos já estudados por Marcos Saquet em outros momentos.

Aos leitores não iniciados na ciência geográfica, a leitura dos textos poderia iniciar-se pelo capítulo 3, escrito por Marcelo Lopes de Souza, que vai direto ao ponto, deslindando o que ele chama de "conceito fundamental". Ao apontar divergências em torno do conceito de território, o autor aproveita para corrigir equívocos na interpretação de seus textos seminais, aos quais seguidamente se reporta, alimentando diálogos críticos e construtivos. A linguagem coloquial que utiliza favorece ao leitor compreender o território nas suas dimensões política, cultural e econômica, além de entrar em contato com os aspectos material e imaterial do território e os desdobramentos quanto aos "territórios autônomos" e à "territorialidade autônoma".

Um pouco mais complexa é a discussão do capítulo 4, que, com Marcos Saquet, vem na sequência. Lembra muito o debate que trouxe em obra intitulada Abordagens e concepções

\footnotetext{
${ }^{1}$ Doutorando em Geografia pela Universidade Federal de Santa Maria (UFSM) e Mestre em Desenvolvimento Regional e Meio Ambiente pela Universidade Estadual de Santa Cruz (UESC); arthur.sturmer@gmail.com.
} 
de território, porém explorando mais a relação entre território e territorialidade através da aproximação das contribuições de Giuseppe Dematteis, Massino Quaini, Claude Raffestin e Robert Sack - autores cujas obras inspiraram as iniciativas de renovação do conceito de território a partir da década de 1990. Contudo, seu foco é a abordagem territorial que confere centralidade aos processos históricos e multiescalares, os quais - afirma - se traduzem no território, territorialidade, desterritorialização e reterritorialização. É uma abordagem de cunho multidimensional, relacional e processual que reconhece a combinação de territorialidade e temporalidades, mudanças e continuidades no tempo e no espaço. A mesma concepção defendida em outro livro, em que já apresentara o território como "espaço de mobilização, organização, luta e resistência política" e a territorialidade como "práxis de transformação do território" (SAQUET, 2015, p. 103), demonstrando rara coerência conceitual em meio às suas inúmeras publicações.

Nesta obra, de modo geral, os dezesseis artigos - correspondentes a igual número de capítulos - contemplam o conceito de território, mas sempre lhe indo além, pois tratam, por exemplo, do espaço-território, entre-território e territorialidade. Quer dizer, dão conta das derivações conceituais do território, ampliando suas possibilidades interpretativas e mostrando suas múltiplas dimensões e interfaces com os demais conceitos, especialmente os de espaço e região.

$\mathrm{Na}$ presente coletânea também se percebe a relação do território com culturas, identidades, representações e formação social brasileira. Os próprios organizadores sinalizam que todos os artigos procuram abordar temas vinculados aos processos sociais e espaciais, senão a ambos. Assim, eles têm em comum o território tomado como "lócus de relações de poder reproduzidas historicamente e em meio às relações sociedade-natureza mediadas por técnicas e tecnologias" (SAQUET e SPOSITO, 2015, p. 11-12). Por isso, suas teorias explicam os processos sem ocultar os conflitos.

Esse ir além do conceito ficou a cargo da experiência de Rogério Haesbaert, no capítulo 5, que adverte de início que a questão central do debate são as problemáticas e o que se faz, concretamente, dos conceitos de território que são construídos. Não obstante, percorre um caminho que vai da definição de conceito, da conceituação de espaço e território, até a aplicação do conceito de território às "problemáticas sociais geo-historicamente contextualizadas" que o moldam. Dentre elas, há a problemática da mobilidade, que recebe sua atenção na tentativa de apreendê-la sob a ótica espacial ou geográfica, com o conceito de "contenção" territorial. Percebe-se um esforço por atualizar a definição, uso e aplicação do conceito de território.

No capítulo 6, Massimo Quaini procura os "sentidos geográficos" presentes na obra de Ítalo Calvino, em especial n'As Cidades Invisíveis, identificando metáforas sobre o território como "prisão-fortaleza", a tensão entre a cartografia de algures e a cartografia do território mais familiar, ou seja, entre o modelo e a realidade, o mapa e o território, a fortaleza perfeita e as verdadeiras - essas as do cotidiano. Aqui se abre espaço para pensar a territorialidade, bem como aceitar a existência da oscilação entre a descrição do presente e a projeção do futuro, o que revela uma concepção de território ligada não apenas à estaticidade da cartografia, mas à dinamicidade da narrativa. Mesmo o mapa enquanto sugere a ideia de "circundamento" próprio do território, já "pressupõe uma ideia de narrativa". No entanto, o enredo d'As Cidades Invisíveis toca em um ponto que Quaini diz faltar à geografia de hoje: a capacidade humana de pensar e ver a liberdade de todos, ao menos como um exercício de pensamento utópico ou de imaginação geográfica.

O capítulo 7 traz a discussão territorial a uma perspectiva mais aplicada, com o conceito de território e de espaço sendo utilizado para a análise da formação social brasileira, não sem apontar as limitações da concepção de "território' dos geógrafos". Sahr e Sahr partem do território paranaense e seus "faxinais", reconhecendo o contraste entre o conceito 
de território na teoria geográfica acadêmica e a vivência dos faxinais "na sua pluralidade". Dialogando com amplo referencial bibliográfico, que conta com autores como Deleuze, Guatarri e Mafessoli, objetivam fornecer um caminho à autonomia e "territorialização alternativa da sociedade (pós-)moderna". Em contraposição ao que chamam de abordagens neo-materialistas, propõem uma linha de fuga à T-D-R (Territorialização-DesterritorializaçãoReterritorialização). Assim, procuram dar, ao longo do texto, mais visibilidade às vivências concretas e autônomas das populações ao tratar do "território".

As populações são assunto do capítulo 8, que versa sobre a mobilidade internacional, assunto tangenciado por Haesbaert em capítulo precedente. Agora, porém, Maria de Almeida usa do conceito de espaço móvel e expressões diretamente relacionadas ao território - interterritorialidade, novas territorialidades e vida entre-territórios - para apreender os processos implicados nas territorialidades dos imigrantes, em especial os brasileiros trabalhadores em Barcelona, Espanha, e sua condição de reterritorializado. A autora ainda guarda preocupação com o contexto da migração das populações - esse "espaço singular" - e os territórios que elas vêm produzindo. Entretanto, a atenção à "mobilidade "sobremoderna" é que atualiza a visão do leitor acerca da "nova era das migrações internacionais" ou diáspora permanente, que cria e alimenta entre-territórios e entre-culturas.

O capítulo 9 dá continuidade ao movimento de reflexão proposto pela obra - de temas mais teóricos aos mais aplicados - encontrando aqui seu ponto de equilíbrio. Na intercalação de autores de maior expressão regional com outros, conhecidos nacionalmente, chega-se a Mançano Fernandes e seu ensaio sobre a tipologia de territórios. Seu texto bem didático ficaria ainda melhor situado se estivesse entre os cinco primeiros, pois faz um breve apanhado da concepção de território que predomina na academia, em políticas públicas e projetos de desenvolvimento, pondo luz à dinâmica de disputas territoriais e aos processos de conflitualidades. Trata-se de uma proposição para a análise dos territórios, e não propriamente do conceito de território - embora o faça de início - ou de territórios específicos. O autor deixa claro a indissociabilidade entre relação de classe e território, afirmando que: "Relações e classes sociais produzem diferentes territórios e espaços que as reproduzem em permanente conflitualidade." (in SAQUET e SPOSITO, 2015, p. 197). Tais relações refletem-se nos três tipos de território que o autor descreve: o primeiro território (espaço de governança), segundo território (propriedade) e terceiro território (espaço relacional).

O capítulo 10 repete o estilo sintético do artigo anterior, o qual se verá mais adiante também, mas sem que se perca em qualidade. Este vem a complementar o que já se falou sobre território ao longo do livro, mas sob outro olhar. O território, aqui, passa a ser o espaço de identidade. Rosa Medeiros traz Bonnemaison para definir o território em função da cultura, ou seja, como lugar de mediação entre homens e sua cultura. Em outras palavras, o território é um espaço cultural de identificação e pertencimento em que se afirma a identidade - no caso posto em análise, identidade de assentado. Ela acaba também se redimensionando como territorialidade, processo que vai revelando a multiplicidade do espaço vivido; isso através do uso do solo, relações de troca e organização do trabalho em um novo "território de múltiplas existências, de diferentes culturas", cuja nova identidade, sócio-política, é fator de unidade.

O leitor habituado à leitura contínua dos capítulos, seguindo a ordem do sumário, há de ter sentido dificuldades em achar aquele fio condutor das discussões, exceto pela menção rápida a um ou outro conceito já comentado em capítulo anterior. Como a obra é uma coletânea de artigos, esse é um aspecto irrelevante, muito embora, quando se chega ao capítulo 10, acima, a impressão é a de que o livro já teria explorado suficientemente o tema do território e das territorialidades, dando uma boa e ampla noção em termos de sua conceituação e aplicação prática como ferramenta de análise.

A partir daí, sente-se o livro estender-se e ser acometido pela recorrência temática, como se vê no capítulo 11, com a migração, o migrante e a mobilidade, mesmo que venha 
EM

articulada com a territorialidade issei e dekassegui. Intercalando autores reconhecidos pelas suas publicações acadêmicas em âmbito nacional com os de menor expressão pode não ser uma boa opção quando se tem nomes como o de Álvaro Heidrich, Candiotto e Fuini às últimas páginas. Não obstante, as 363 páginas são justificadas por trazer contribuições importantes de cada autor: Governa e o desenvolvimento local (capítulo 12); Heidrich e os conflitos/vínculos territoriais (capítulo 13); Fuini e sua governança territorial (capítulo 14); Candiotto e a utilização da abordagem territorial a diversos temas (capítulo 15), finalizando com Souza (capítulo 16), que entrelaça território e região para falar das políticas públicas não sem contextualizá-la em referência à já mencionada Região Oeste do Paraná.

De um modo geral, Territórios e territorialidades: teorias, processos e conflitos atende ao intento de "discutir o conceito de território", contribuindo para dissipar a noção de território como categoria da prática e firmá-lo como categoria de análise da prática social efetiva. Isso foi bem demonstrado nas abordagens dos conflitos, contenções e disputas territoriais, destacadamente aquelas que envolvem os movimentos sociais e as novas territorialidades. Faz-se jus, entrementes, ao subtítulo "teorias, processos e conflitos", pois esse é o conteúdo da obra, que às vezes é denso, mas sem ser maçante; também se mostra compromissado, mas sem exigir proselitismo. Enfim, é uma obra recomendada tanto para leitores iniciados quanto para os mais experimentados e pesquisadores da ciência geográfica, devido à variedade dos níveis de aprofundamento teórico dos textos e pela atraente diversidade temática.

\section{Referências}

RIBAS, A. D.; SPOSITO, E. S.; SAQUET, M. A. (Orgs.). Território e desenvolvimento: diferentes abordagens. Francisco Beltrão: Unioeste, 2004.

SAQUET, M. A. Abordagens e concepções de território. 3. ed. São Paulo: Outras Expressões, 2013.

A. Por uma geografia das territorialidades e das temporalidades: uma concepção multidimensional voltada para a cooperação e para o desenvolvimento territorial. 2. ed. Rio de Janeiro: Consequência, 2015.

SAQUET, M. A.; SPOSITO, E. S. (Orgs.). Territórios e territorialidades: teorias, processos e conflitos. 2. ed. Rio de Janeiro: Consequência, 2015.

Resenha recebida em 28-01-2019

Resenha aceita para publicação em 19-12-2019 